\title{
Evolução hemodinâmica seqüencial no transplante cardíaco
}

Noedir A. G. STOLF*, Alfredo I. FIORELLI*, Edimar A. BOCCHI*, Jorge M. PASCUAL, José Otávio C. AULER JÚNIOR*, Pedro Carlos P. LEMOS*, Fábio B. JATENE*, Pablo M. POMERANTZEFF*, Giovanni BELLOTTI I*, Fúlvio PILEGGI*, Adib D. JATENE*

STOLF, N. A. G.; FIORELLI, A. I.; BOCCHI, E. A.; PASCUAL, J. M.; AULER JÚNIOR, J. O. C.; LEMOS, P. C. P.; JATENE, F. B.; POMERANTZEFF, P. M.; BELlOtTI, G.; PILEGGI, F.; JATENE, A. D. Evolução hemodinâmica seqüencial no transplante cardiaco. Rev. Bras. Cir. Cardiovasc., 3(3): 189-195, 1988.

RESUMO: O transplante cardiaco tem tido ampla aplicação no tratamento da cardiomiopatia em fase terminal. Grande interesse existe no estudo das alterações hemodinâmicas imediatas e na identificaçāo dos fatores que determinam essas alteraçōes. Quarenta e três pacientes transplantados foram estudados com esse objetivo. Os seguintes dados foram obtidos: índice cardiaco, as pressōes nas câmaras cardíacas, capilar pulmonar, aorta, artéria pulmonar, volume sistólico, fração de ejeçāo do ventrículo esquerdo (VE), resistência vascular pulmonar e sistêmica, índice do trabalho sistólico do ventrículo esquerdo e direito (VD) e o tríplice produto. Esses valores foram comparados de acordo com os episódios de rejeição e com diferentes valores do gradiente transpulmonar. Verificou-se que no pós-operatório imediato há depressão da funçâo dos ventriculos decorrente de uma série de fatores. $O$ indice cardíaco se mantém em valore adequados através de vários mecanismos e adaptaçâo dos ventriculos, que ocorre mais precocemente para o VE do que para o VD. Tardiamente as alteraçōes hemodinâmicas dependem do aparecimento de hipertensão arterial sistêmica e da aterosclerose coronária. A presença e os valores mais elevados do gradiente transpulmonar não tiveram influência estatisticamente significativa nas condições hemodinâmicas dos pacientes.

DESCRITORES: transplante cardiaco, hemodinâmica; transplante cardiaco.

\section{INTRODUÇÃO}

O transplante cardiaco apresenta-se, atualmente, como a principal alterantiva terapêutica para os pacientes portadores de cardiomiopatia terminal. A introdução da ciclosporina A no esquema imunossupressor, associado a uma série de outros avanços, melhorou os resultados a longo prazo desse procedimento. Esses fatores foram os principais responsáveis pelo aumento progressivo do número de transplantes em todos os Centros do mundo ${ }^{2,6}$.

O conhecimento do comportamento funcional do co- ração desnervado é um importante fator no seguimento clínico desses pacientes. Vários estudos experimentais ${ }^{3}$ e clínicos ${ }^{8}$ têm contribuido na avaliação das alteraçōes hemodinâmicas frente a diferentes fatores, tais como: esquemas de imunossupressão, tempo de isquemia do órgão e o exercício físico ${ }^{7 \cdot 10}$.

O presente trabalho tem por finalidade estudar o comportamento hemodinâmico após o transplante cardíaco, considerando-se o periodo de pós-operatório imediato e as alterações que se instalam posteriormente, devido às drogas imunossupressoras e aos episódios de rejeição.

\footnotetext{
Trabalho realizado no Intituto do Coração do Hospital das Clínicas da Faculdade de Medicina da Universidade de São Paulo. São Paulo, SP, Brasil Apresentado ao 15: Congresso Nacional de Cirurgia Cardiaca. Rio de Janeiro, RJ, 7 e 8 de abril, 1988.

- Do Instituto do Coraçấo do Hospital das Clinicas da Faculdade de Medicina da Universidade de Săo Paulo.

Endereço para separatas: Noedir Stolf. Av. Dr. Eneas Carvalho de Aguiar, 44. Divisão Cirúrgica. 05403 São Paulo, SP, Brasil.
} 
STOLF, N. A. G.; FIORELLI, A. I.; BOCCHI, E. A.; PASCUAL, J. M.; AULER JÚNIOR, J. O. C.; LEMOS, P. C. P.; JATENE, F. B.; POMERANTZEFF, P. M.; BELLOTTI, G.; PILEGGI, F.; JATENE, A. D. - Evolução hemodinâmica seqüencial no transplante cardiaco. Rev. Bras. Cir. Cardiovasc., 3(3): 189-195, 1988.

\section{CASUISTICA E MÉTODOS}

No período de março de 1985 a março de 1988 (36 meses), 43 pacientes portadores de insuficiência cardíaca em clase funcional IV (NYHA), em fase terminal, foram submetidos a transplante cardíaco ortotópico. As principais indicaçōes para o transplante foram: cardiomiopatia dilatada em $19(44,2 \%)$ casos, isquêmica em $16(37,3 \%)$ casos, chagásica em $6(13,9 \%)$ casos, reumática em $1(2,3 \%)$ caso e congênita em $1(2,3 \%)$ caso. A idade variou de 3 a 60 anos (média 42,7 anos), sendo que $38(88,4 \%)$ eram do sexo masculino. A técnica operatória empregada foi aquela classicamente descrita pelo grupo de Stanford. A idade média dos doadores foi de 23-9 anos, com peso corpóreo superior ao do receptor em $20,3(10 \%)$. O tempo médio de isquemia do órgão foi de $160-50$ minutos.

O cateterismo cardiaco fez parte do protocolo de avaliação hemodinâmica pré-operatória e para complementação diagnóstica. A monitorização hemodinâmica imediata, considerada até o terceiro dia pós-transplante, foi realizada com auxílio do cateter de Swan-Ganz para as determinaçōes pressóricas em átrio direito (AD), artéria pulmonar (AP) e capilar pulmonar (CP). $\mathrm{O}$ débito cardíaco foi obtido pelo método de termodiluição. No período tardio, essa mesma técnica foi empregada durante as biópsias endomiocárdicas de rotina, com as determinaçōes hemodinâmicas acima consideradas. As medidas foram realizadas com o paciente em decúbito dorsal horizontal e em repouso. $\mathrm{O}$ critérios de rejeição estão de acordo com os descritos por BILLINGHAM '. O cateterismo cardíaco completo foi reealizado rotineiramente a cada 12 meses, para avaliação das artérias coronárias e da contratilidade ventricular, sendo estudados $14(32,5 \%)$ pacientes no primeiro ano e $4(9,3 \%)$ no segundo ano de evolução. As determinaçōes de índice cardíaco (IC), volume sistólico (VS), resistência vascular pulmonar (RVP), resistência vascular sistêmica (RVS), indice do trabalho sistólico de ventrículo direito (ITSVD), indice do trabalho sistólico de ventrículo esquerdo (ITSVE) e o tríplice produto (TP) foram calculados pelas equaçōes classicamente conhecidas. A fração de ejeção (FE) foi obtida pela variação numérica da área na ventriculografia em posiçẫo obliqua direita. Somente os episódios de rejeição, moderada e severa, que exigiram pulsoterapia venosa ou oral, foram considerados na análise comparativa dos dados hemodinâmicos. Os estudos comparativos entre os diferentes grupos foram analisados pelo teste $T$ pareado com significância de 0,05 .

\section{RESULTADOS}

A Tabela 1 apresenta os valores médios e desvio padrão da freqüência cardiaca $(F C)$, índice cardíaco $(I C)$, pressão em átrio direito $(A D)$, capilar pulmonar $(C P)$ e pressão arterial média (PAM) no pós-operatório imedia-

\section{TABELA 1}

\begin{tabular}{crrrrrr}
\hline & $\begin{array}{c}A D \\
(\mathrm{mmHg})\end{array}$ & $\begin{array}{c}C P \\
(\mathrm{mmHg})\end{array}$ & $\begin{array}{c}P A M \\
(\mathrm{mmHg})\end{array}$ & $\left.\begin{array}{c}F C \\
(b a t / \mathrm{min})\end{array}(\mathrm{R} / \mathrm{min} \mathrm{m})^{2}\right)$ \\
\hline Pré & $8 \pm 5$ & $20 \pm 8$ & $78 \pm 8$ & $98 \pm 18$ & $1,7 \pm 0,6$ \\
Doador & $3 \pm 2$ & $10 \pm 4$ & $61 \pm 5$ & $90 \pm 10$ & $3,5 \pm 0,5$ \\
PO* & $13 \pm 5$ & $13 \pm 4$ & $77 \pm 9$ & $106 \pm 13$ & $3,0 \pm 1,0$ \\
PO. $^{*}$ & $13 \pm 4$ & $13 \pm 3$ & $81 \pm 4$ & $89 \pm 14$ & $3,1 \pm 0,8$ \\
PO* $^{*}$ & $14 \pm 4$ & $14 \pm 4$ & $86 \pm 13$ & $90 \pm 14$ & $3,2 \pm 1,0$ \\
PO* $^{*}$ & $15 \pm 7$ & $13 \pm 7$ & $76 \pm 7$ & $98 \pm 14$ & $3,6 \pm 1,0$ \\
\hline
\end{tabular}

- PO - Pós operatório

to. Nota-se a redução progressiva da pressão em capilar pulmonar, o aumento do indice cardíaco e da pressão atrial direita. Na Tabela 2, acham-se os valores hemodinâmicos derivados: resistēncia vascular pulmonar, resistência vascular sistêmica, índice do trabalho sistólico de ventrículo direito, índice do trabalho sistólico do ventrículo esquerdo, tríplice produto e índice sistólico. Os cálculos do índice de trabalho sistólico e do tríplice produto são extremamente úteis, pois estão diretamente relacionados com a contratilidade ventricular e o consumo de oxigênio pelo miocárdio. Após o transplante, há redução de $50 \%$ nas resistências vasculres e no tríplice produto, enquanto que $o$ índice sistólico e o índice do trabalho sistólico ventricular esquerdo dobram os seus valores. $\mathrm{O}$ aumento no índice de trabalho sistólico ventricular direito à menos acentuado.

TABELA 2

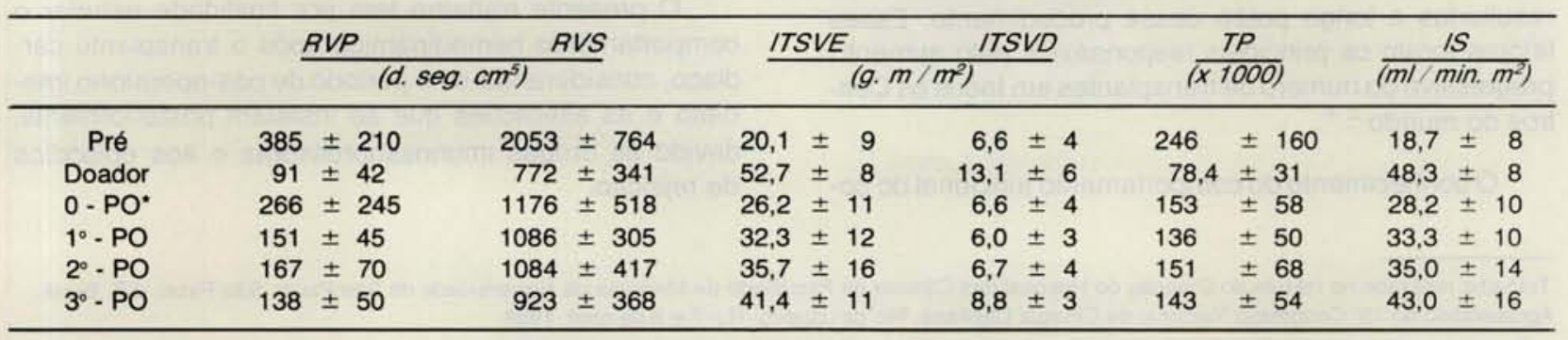

- PO - Pós operatório 
STOLF, N. A. G.; FIORELLI, A. I.; BOCCHI, E. A.; PASCUAL, J. M.; AULER JÚNIOR, J. O. C.; LEMOS, P. C. P.; JATENE, F. B.; POMERANTZEFF, P. M.; BELLOTTI, G.; PILEGGI, F.; JATENE, A. D. - Evolução hemodinâmica seqüencial no transplante cardiaco. Rev. Bras. Cir. Cardiovasc., 3(3): 189-195, 1988.

TABELA 3

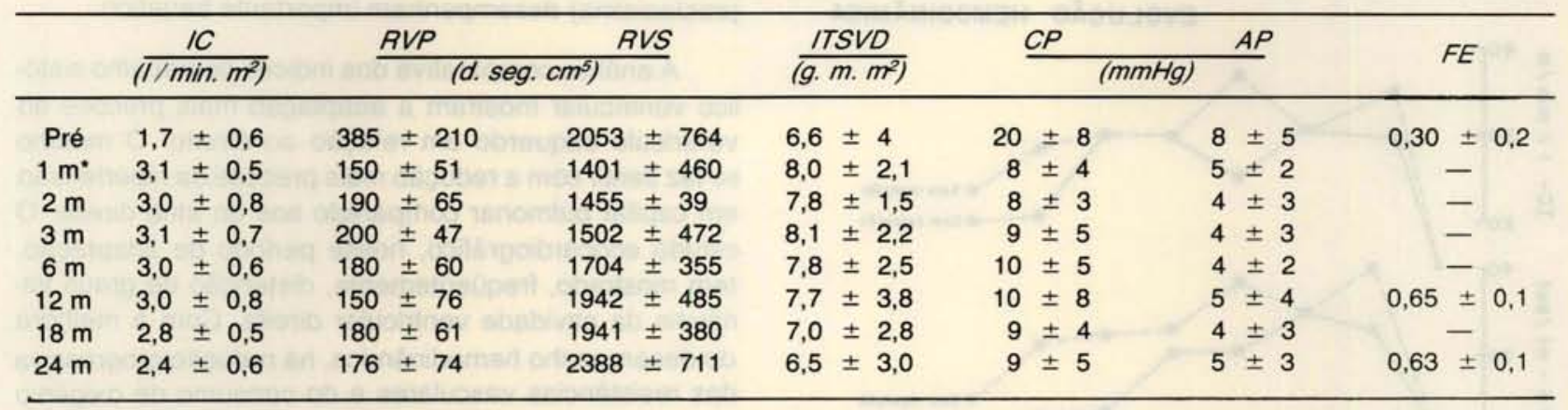

*m - mesies

Para se avaliar o papel do gradiente transpulmonar na evolução pós-operatória, os pacientes foram divididos em 2 grupos: Grupo I) com gradiente menor que 15 $\mathrm{mmHg}$ e Grupo II) com gradiente maior ou igual a 15 $\mathrm{mmHg}$.

O Grupo I foi formado por 25 pacientes $(58,1 \%)$ e o Grupo II, por 18 pacientes $(41,9 \%)$. A Figura 1 apresenta a análise comparativa desses 2 grupos de pacientes, considerando-se as seguintes variáveis: pressão de átrio direito, capilar pulmonar, os índices de trabalho sistólico-ventricular e as resistências vasculares. Não se observaram alteraçōes hemodinâmicas significativas entre os grupos analisados, no período considerado. A mortalidade geral imediata, no Grupo I, foi de $12,0 \%$ e, no Grupo II, de $16,7 \%$, sendo que a mortalidade imediata foi de $13,9 \%$

A Tabela 3 apresenta os valores médios das variáveis hemodinâmicas obtidas no pré e no pós-operatório tardio, durante as biópsias endomiocárdicas de rotina. A fração de ejeção foi obtida nos cateterismos realizados anualmente. Somente 1 paciente desenvolveu obstrução coronária precoce grave no primeiro ano de evolução, com importante deficit contrátil, estando, atualmente, em calsse funcional II - III (NYHA), em programa de retransplante. A Figura 2 apresenta variação do índice cardiaco, volume sistólico e pressão em capilar pulmonar, durante os episódios de rejeição e na ausência dos mesmos. Nota-se tendência a redução do índice cardiaco e volume sistólico e aumento da pressão capilar pulmonar durante os episódios de rejeição, apesar de não existir diferença estatisticamente significativa $(p<0,05)$.

Os desempenhos das câmaras cardíacas direitas acham-se apresentadas na Figura 3-A, notando-se a manutençāo dos níveis pressóricos dentro dos limites da normalidade, após 24 meses de evolução. Na Figura 3-B, pode-se observar o perfil evolutivo da resistência vascular pulmonar e sistêmica, durante o período considerado. Hipertensão arterial sistêmica ocorreu em $69 \%$ dos pacientes com mais de 1 ano de evolução, sendo necessária terapia específica. O comportamento da pressão arterial no transplante cardiaco pode ser anali- sado na Figura 4. Nota-se que, a partir do terceiro mês de evolução, há aumento progressivo das pressões sistólicas, estabilizando-se a partir do primeiro ano.

\section{TRANSPLANTE CARDIACO}
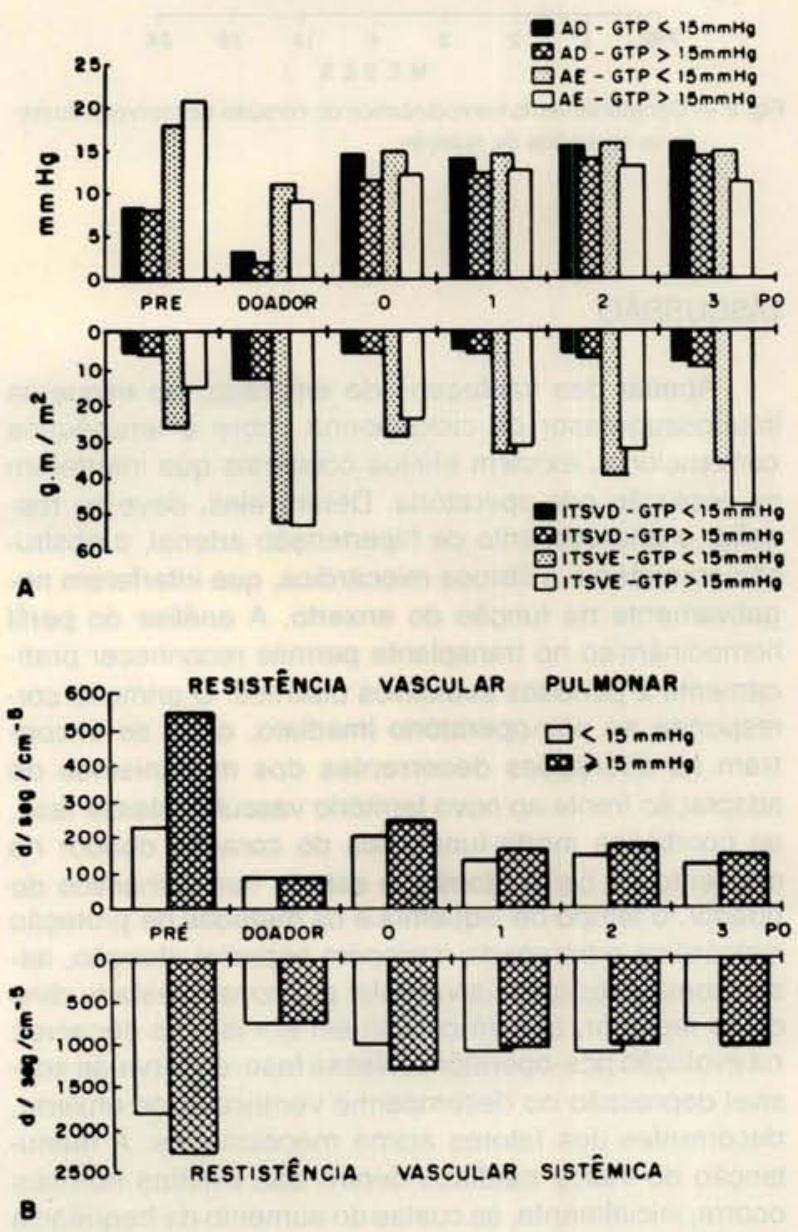

Fig. 1 - Análise comparativa, em A, das pressōes em átrio direito (AD) - capilar pulmonar (CP) e dos indices de trabalho sistólico ventricular esquerdo (ITSVE)- direito (ITSVD) e, em B, das resistências vasculares sistêmica (RVS) e pulmonar (RVP), em função do gradiente transpulmonar (GTP) pré-operatório. O perfil evolutivo não mostra diferenças significativas $(p<0,05)$. 
STOLF, N. A. G.; FIORELLI, A. I.; BOCCHI, E. A.; PASCUAL, J. M.; AULER JÚNIOR, J. O. C.; LEMOS, P. C. P.; JATENE, F. B.; POMERANTZEFF, P. M.; BELLOTTI, G.; PILEGGI, F.; JATENE, A. D. - Evolução hemodinâmica seqüencial no transplante cardiaco. Rev. Bras. Cir. Cardiovasc., 3(3): 189-195, 1988.

TRANSPLANTE DE CORACAO EVOLUCĀO HEMODINĀMICA

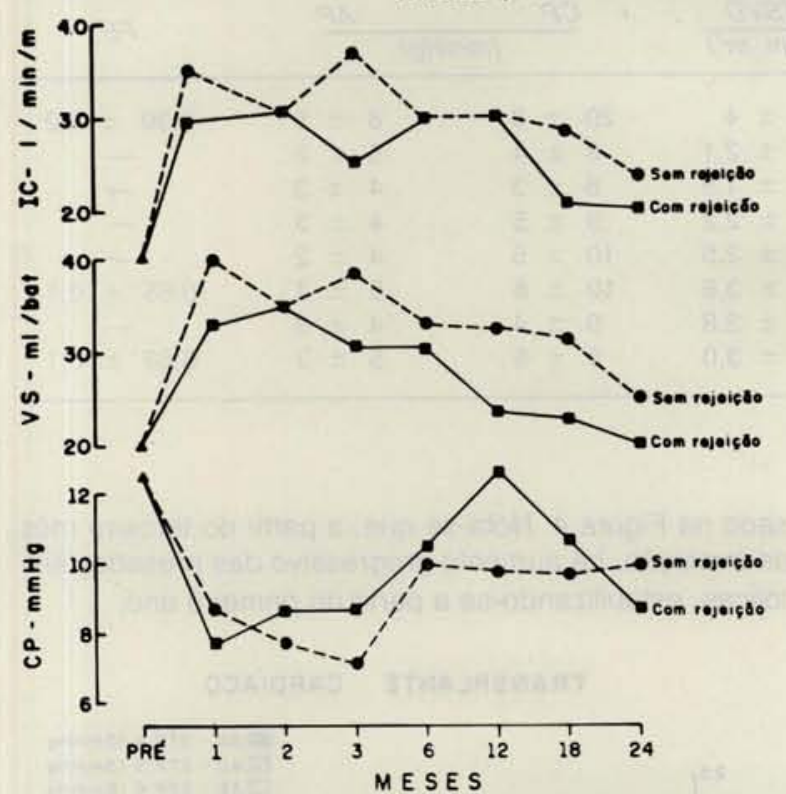

Fig. 2 - Comportamento hemodinâmico do coração desnervado durante os episódios de rejeição.

\section{DISCUSSĀO}

Apesar das vantagens do emprego, no esquema imunossupressor da ciclosporina sobre a terapêutica convencional, existem efeitos colaterais que interferem na evolução pós-operatória. Dentre eles, deve-se ressaltar o aparecimento de hipertensão arterial, a obstrução coronária e a fibrose miocárdica, que interferem negativamente na função do enxerto. A análise do perfil hemodinâmico no transplante permite reconhecer praticamente 2 períodos evolutivos distintos. $\mathrm{O}$ primeiro corresponde ao pós-operatório imediato, onde se encontram as alteraçōes decorrentes dos mecanismos de adaptação frente ao novo território vascular. Nessa fase, as condiçōes morfo-funcionais do coração doador no momento da cardiectomia, o estado hemodinâmico do doador, o tempo de isquemia e os métodos de proteção miocárdica empregada merecem especial atenção, assim como a resistência vascular pulmonar o estado clínico do receptor, que se constituem em fatores decisivos na evoluçāo pós-operatória. Nessa fase, observa-se sensível depressão no desempenho ventricular do enxerto, decorrentes dos fatores acima mencionados. A manutenção do índice cardiaco dentro dos limintes normais ocorre, inicialmente, às custas do aumento da freqüência cardiaca e, posteriormente, devido ao aumento do índice sistólico. O ventrículo direito normal não é suficientemente hipertrofiado para vencer a resistência vascular pulmonar do receptor, tornando-se a câmara de choque no transplante. Nesta fase, o uso de catecolaminas (do- pamina-adrenalina) e vasodilatadores (nitroprussiatoprostaciclina) desempenham importante benefíco.

A análise comparativa dos índices de trabalho sistólico ventricular mostram a adaptação mais precoce do ventrículo esquerdo em relação ao direito. $\mathrm{O}$ mesmo se faz sentir com a redução mais precoce da hipertensão em capilar pulmonar comparado aos do átrio direito. $O$ estudo ecocardiográfico, nesse periodo de adaptação, tem mostrado, freqüentemente, distençāo de graus variáveis da cavidade ventricular direita. Com a melhora do desempenho hemodinâmico, há reduçāo progressiva das resistências vasculares e do consumo de oxigênio pelo miocárdio (tríplice produto) em relação ao periodo pré-operatório.

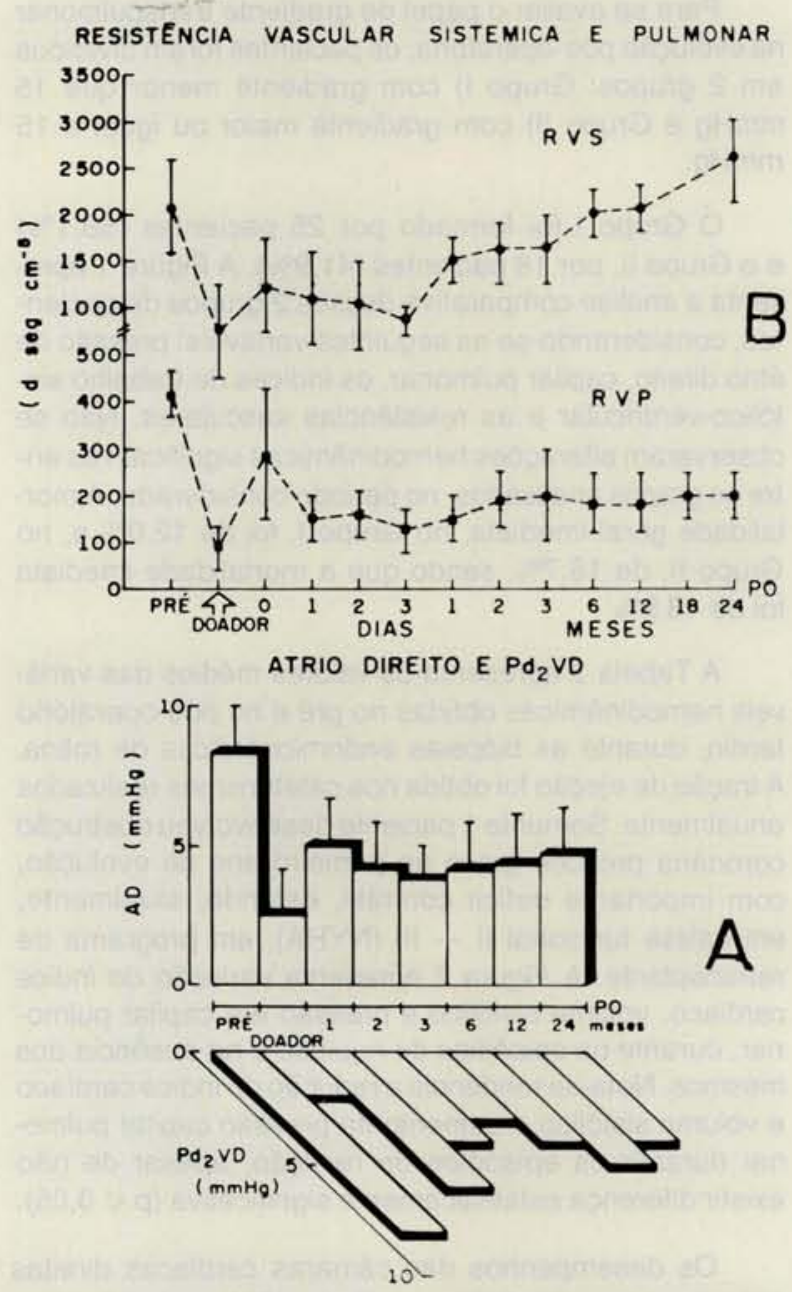

Fig. 3 - Evolução hemodinâica tardia das cầmaras cardiacas direitas (A) e das resistências vasculares (B).

Recentemente, tem-se enfatizado que o gradiente transpulmonar é um parâmetro preditivo melhor da sobrevida imediata pós-transplante ${ }^{7}$. Procurando-se avaliar a influência desse índice na evolução hemodinâmica, os pacientes foram divididos em 2 grupos. $O$ estudo comparativo não mostrou diferenças significativas entre 
STOLF, N. A. G.; FIORELLI, A. I.; BOCCHI, E. A.; PASCUAL, J. M.; AULER JÚNIOR, J. O. C.; LEMOS, P. C. P.; JATENE, F. B.; POMERANTZEFF, P. M.; BELLOTTI, G.; PILEGGI, F.; JATENE, A. D. - Evolução hemodinâmica seqüencial no transplante cardiaco. Rev. Bras. Cir. Cardiovasc., 3(3): 189-195, 1988.

eles, apesar dos pacientes do Grupo I evoluírem com pressão em átrio direito e resistência vascular e pulmonar em niveis superiores. No entanto, a mortalidade imediata foi superior no Grupo II, em relação ao I.

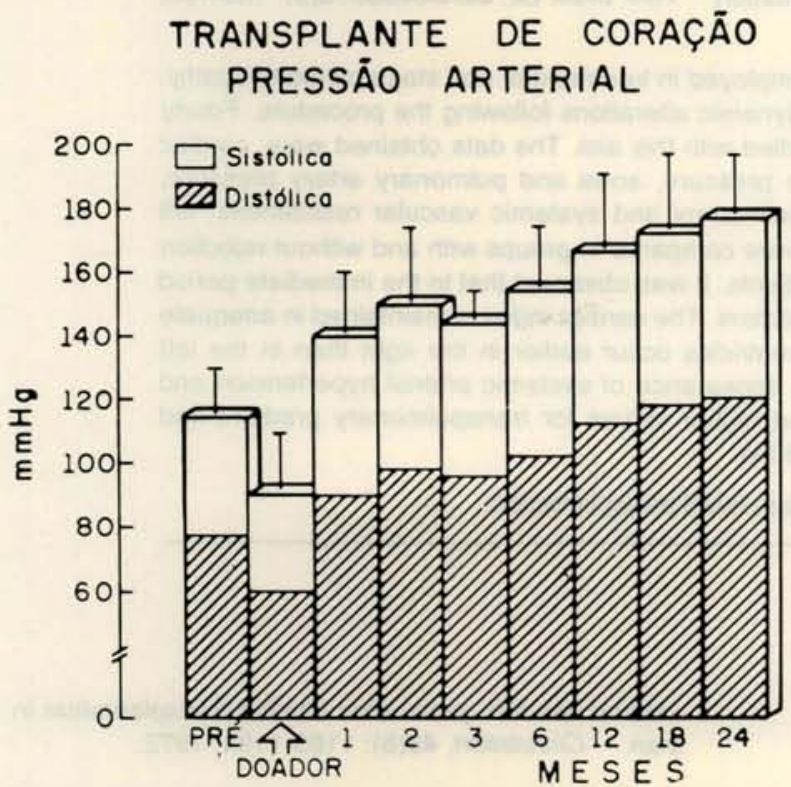

Fig. 4-Comportamento da pressâo arterial após o transplante cardíaco, notando-se o aparecimento de hipertensăo a partir do primeiro trimestre.

Após o primeiro mês de evolução, quando os principais mecanismos básicos de adaptação já se instalaram, outros fatores passam a exercer influência sobre o coração transplantado. Os episódios de rejeição e os efeitos colaterais das drogas imunossupressoras inteferem negativamente na função miocárdica. A hipertensão arterial é uma observação freqüente nos pacientes transplantados, ocorrendo, nesta série, em $69,0 \%$ dos pacientes, com mais de 1 ano de evolução. Tem-se observado que o desenvolvimento de hipertensão é relativamente resistente ao tratamento e associa-se a disfunção renal. A nefrotoxicidade é dose dependente e reversível, cujo mecanismo de ação é discutivel, tendo-se observado regressão com a suspensão da ciclosporina. THOMPSON et alii ${ }^{9}$ têm observado valores normais da atividade de renina plasmática e dos níveis de catecolamina na urina, em pacientes com o uso de ciclosporina. No esquema convencional com azatioprina e predinizona, o desenvolvimento de hipertensão é menos freqüente. Demonstrou-se a elevação progressiva da resistência vascular sistêmica, devido ao aparecimento de hipertensão. A resistência vascular pulmonar, assim como o desempenho de ventrículo direito, mantém-se dentro dos limites normais.

A fração de ejeção média também se manteve inalterada, nesse período. Apenas um paciente desenvolveu redução acentuada da fração de ejeção e do índice cardíaco, conseqüente a obstrução coronária e fibrose miocárdica. Essas alteraçōes ocorrem devido a vasculite e posterior obstruçāo, secundária a um processo de rejeição crônico.

Em todos os pacientes assintomáticos, a arteriografia coronária estava normal. GREENBERG et alii ${ }^{4}$, analisando a fração de ejeção e a pressão diastólica final de ventrículo esquerdo em pacientes com diferentes índices de rejeição, não encontrou diferenças significativas. A disfunção ventricular esquerda e a aterosclerose coronária acelerada ocorrem como manifestação de rejeição crônica ${ }^{5}$.

Quando comparadas, as alterações hemodinâmicas, na vigência ou não de rejeição, observa-se tendência a redução do índice cardíaco e volume sistólico, porém as variaçōes não são significativas. Em ambas as situaçōes, os pacientes estavam assintomáticos. Com o uso da ciclosporina, as crises de rejeição, na fase inicial, ocorreram sem manifestações clínicas de disfunção ventricular.

Concluindo, os pacientes submetidos a transplante cardiaco que recebem ciclosporina no esquema imunossupressor apresentam, tardiamente, alteraçōes hemodinâmicas, principalmente devido a hipertensão arterial, ou a aterosclerose coronária acelerada. Durante os episódios de rejeição, que exigiram pulsoterapia (moderadasevera), não se observaram alteraçōes hemodinâmicas significativas em repouso. No pós-operatório imediato, há depressão miocárdica, devido à adaptação do enxerto às novas condiçōes e o ventrículo direito exige maior tempo de recuperação em relação ao esquerdo. 
STOLF, N. A. G.; FIORELLI, A. I.; BOCCHI, E. A.; PASCUAL, J. M.; AULER JÚNIOR, J. O. C.; LEMOS, P. C. P.; JATENE, F. B.; POMERANTZEFF, P. M.; BELLOTTI, G.; PILEGGI, F.; JATENE, A. D. - Evolução hemodinâmica seqüencial no transplante cardiaco. Rev. Bras. Cir. Cardiovasc., 3(3): 189-195, 1988.

\section{RBCCV 44205-66}

STOLF, N. A. G.; FIORELLI, A. L.; BOCCHI, E. A.; PASCUAL, J. M.; AULER JÚNIOR, J. O. C.; LEMOS. P. C. P.; JATENE, F. B.; POMERANTZEFF, P. M.; BELLOTTI, G.; PILEGGI, F.; JATENE, A. D. Sequential hemodynamic evaluation in heart transplantation. Rev. Bras. Cir. Cardiovasc., 3(3): 189-195, 1988.

ABSTRACT: heart transplantation has been widely employed in treatment of end stage cardiomyopathy. Great interest exists in the study of early and late hemodynamic alterations following the procedure. Fourty three patients submited to heart transplantation were studied with this aim. The data obtained were: cardiac index, pressure in the heart chambers, capillary wedge pressure, aorta and pulmonary artery pressure, systolic volume and ejection fraction of left ventricle, pulmonary and systemic vascular resistances; left and right work systolic indexes; triple product. The data were compared in groups with and without rejection and in groups with higher and lower transpulmonary gradients. It was observed that in the immediate period there was impairment of ventricle function due to several factors. The cardiac index is maintained in adequate levels through several mechanisms, adaptation of the ventricles occur earlier in the right than in the left ventricle; lately hemodynamic alterations depend on the appearance of systemic arterial hypertension and coronary atherosclerosis. The presence of rejection and higher values for transpulmonary gradient had no statistically significant influence in hemodynamic condition.

DESCRIPTORS: heart transplantation, hemodynamics; heart transplantation

\section{REFERÊNCIAS BIBLIOGRÁFICAS}

1 BILLINGHAM, M. E. - Diagnosis of cardiac rejection by endomyocardial biopsy Heart Transpl., 1:25, 1981.

2. BOREL, J. F.; FEUER, C.; GUBLER, H. V.; STAHELIN, I. - Biological effects of cyclosporin A: a new antilymphocyte agent Agents Activans, 6: 468-475, 1976.

3. CHARTRAND, C.; BRYAN, B.; KOSEK, J. E.; DONG, E.; ANGEL, N. W.; SHYMWAY, N. E. - Hemodynamics of the orthotopic homotransplanted canine heart Ann. Thorac. Surg., 13(1), 15-26, 1972.

4. GREENBERG, M. L.; URETSKY, B. F.; REDDY, S.; BERNSTEIN, R. L.; GRIFFITH. B. P.; HARDESTY, R. L.; THOMPSON, M. E.; BAHNSON, H. T. - Long term hemodynamic follow-up of cardiac transplant patients treated with cyclosporine and perdinisone. Circulation, 71(3): 487-494, 1985.

5. HESS, M. L.; HASTILLO, A.; MOHANAKUMAR, T.; WOLFGANG, T.; LOWER, R. P. - Accelerated atherosclerosis in cardiac transplantation: role of cytotoxic B - cells antibodies and hyperlipidemia Circulation, 66(Supl 2): 94, 1982.

6. KAYE, M. - The registry of International Society for Heart Transplantation: fourth official report, 1987. J. Heart. Transp. 6(2): 63-67, 1987.

7. KORMOS, R. L.; THOMPSON, M.; HARDESTY, R. L.; GRIFFITH, B. P.; TRENTO, A.; URETSKY, B. F.; Utility of preoperative right catheterization data as a prediction of survival after heart transplantation, J. Heart. Transpl. 5(5): 391, 1986.

8. STINSON, E. B.; GRIEPP, R. B.: SCHROEDER, J. S.; DONG, E.; SHUMWAY, N. E. - Hemodynamic obser- vations one two years after cardiac transplantation in man. Circulation, 45(6): 1183-1194, 1972.

9. THOMPSON, M. E.; SHAPIRO, A. P.; JOHNSON, A. M.; REEVES, R.; ITZKOFF, I.; GINCHEREAN, E.; HARDESTRY, R. L.; GRIFFITH, B. L.; BAHNSON, H. T.; McDONALD, R. - New onset of hypertension following cardiac transplantation: a preliminary report and analysis. Transpl. Proc. 15: 2573, 1983.

10. TRENTO, A.; HARDESTY, R. L.; GRIFFITH, B. P.; KORMOS, R. L.; BAHNSON, H, T. - Early function of cardiac homografts: relationship to hemodynamics in the donor and length of the ischemic period. Circulation, 74(Supl 3): 77-79, 1986

\section{Discussão}

\section{DR. IVO NESRALLA \\ Porto Alegre, RS}

Gostariamos de fazer dois comentários ao trabalho do $\mathrm{Dr}$. Noedir Stolf. O primeiro, diz respeito às crises de HAP, que costumam ocorrer nas primeiras 48 horas de pós-operatório e suas repercussões sobre o débito cardiaco sistêmico. Em nossa casuística, isto ocorreu em 4 dos 7 pacientes transplantados, mas com pronta resposta ao emprego da dobutamina. Chamou-nos a atenção que tais crises não guardam nenhuma relação com o grau prévio de HAP, ocorrendo até mesmo em pacientes com resistência $V$ pulmonar de 2 unidades Wood. O segundo comentário diz respeito à evoluçāo da RVS conseqüente a HAS, pelo uso da ciclosporina 
STOLF, N. A. G.; FIORELLI, A. I.; BOCCHI, E. A.; PASCUAL, J. M.; AULER JÚNIOR, J. O. C.; LEMOS, P. C. P.; JATENE, F. B.; POMERANTZEFF, P. M.; BELLOTTI, G.; PILEGGI, F.; JATENE, A. D. - Evolução hemodinâmica seqüencial no transplante cardiaco. Rev. Bras. Cir. Cardiovasc., 3(3): 189-195, 1988.

Esta evolução pode comprometer, a médio prazo, o sucesso do transplante. O que observamos, em nossa série, é que, com o emprego do esquema ciclosporina + corticóide, o controle da HAS torna-se mais difícil, mesmo com o uso de betabloqueador e antagonistas do cálcio. Por outro lado, quando empregamos o esquema tríplice (nos 3 últimos pacientes), o controle da HAS tornou-se bem mais fácil. Gostariamos de saber se o colega observou evolução semelhante.

\section{DR. DANTON LOURES Curitiba, $P R$}

Quero cumprimentar o Dr. Noedir Stolf e seus colaboradores, pelo trabalho apresentado. Depreendemos, dessa monitorização hemodinâmica, alguns aspectos: 19) as alterações ocorridas com o débito cardíaco, índice cardiaco, resistência pulmonar e resistência arterial sistêmica, no período de pós-operatório imediato, são muito semelhantes àquelas de pacientes submetidos a correçōes cardiovasculares com circulaçăo extracorpórea; 2:) foi útil para orientação do momento e escolha medicamentosa; $3^{\circ}$ ) no periodo de pós-operatório tardio, houve comprovaçāo do aumento da resistência arterial sistêmica; 4․) a metodologia empregada em ambos os periodos foi invasiva e múltipla. Assim sendo, o estudo da evolução hemodinâmica seqüencial no transplante cardiaco é válido. Quero, entretanto, trazer à apreciação dos autores outra forma de obter as mesmas informaçóes aqui mencionadas e de maneira não invasiva. Recentemente, iniciamos o emprego da bioimpedância com um aparelho da Biomed Medical Manufacturing e nos tem possibilitado informaçōes de: débito cardiaco, índice cardiaco, volume sistólico, índice de fluxo torácico, tempo de ejeçāo ventricular, indice de velocidade de ejeção e fração de ejeção. É um procedimento simples, não invasivo, sensivel, de baixo custo, instantâneo e com possibilidade de monitorização simultânea dos dados hemodinâmicos, batimento a batimento cardíaco, ou com a captação da média dos dados de 12 batimentos. Frente aos seus resultados e a estas ponderaçóes, perguntaria ao Dr. Noedir: 19) a hipertensão arterial sistêmica observada no POT poderá ser um elemento para modificar a posologia e/ou o tipo de imunossupressor? 2:) como considera o emprego de métodos não invasivos para a monitorizaçāo hemodinâmica? Uma vez mais, cumprimento o Dr. Noedir Stolf e seus colaboradores, por sua contribuição à cardiologia e, particularmente, à cirurgia cardiaca.

\section{DR. STOLF \\ (Encerrando)}

Agradeço aos Drs. Ivo Nesralla e Danton Loures as observaçōes e as questōes levantadas, em relação à hipertensão pós-operatória. Como é bem conhecido, ela representa um fator de morbidade e, inclusive, fator de alta mortalidade pós-transplante cardiaco. Nós tivemos esse tipo de complicação logo após o transplante, em alguns doentes e pelo menos 6 foram de magnitude tal que exigiram, inclusive, o uso, que nós consideramos à disponibilidade efetiva, da prostaciclina. Nós usamos, em 6 pacientes, com reversão da hipertensão pulmonar muito rápida, muito drástica e com redução da resistência vascular sistêmica. As prostaglandinas, especialmente a prostaciclina, são uma alternativa que pode baixar a morbidade e a mortalidade por hipertensão pulmonar. Em relação, à observação do $\mathrm{Dr}$. Ivo, nós, realmente, estamos buscando; é um estudo que estamos preparando e que eu acho que possa ser de uma grande importância, para nós, que é procurar os determinantes dessa severa complicação. Em relação à questão também levantada pelo $\mathrm{Dr}$. Ivo, nós já temos uma população pequena, mas bem estudada, do ponto de vista coronariográfico, ao fim do primeiro ano, e ao fim do segundo ano, e já vários doentes ao fim do terceiro ano, além de 1 paciente que tinha alterações obstrutivas muito importantes; os demais, por mais que insistissemos, ou questionássemos as mínimas alteraçōes, eu, pessoalmente, considero que tinham coronárias normais, aparência de fluxo normal; não sei se a ciclosporina, que tem um potente efeito vascular sistêmico, explica a hipertensão arterial; a hipertensão pós-operatória, depois de 3 ou 4 anos de transplante, tem sido, inclusive, uma razão para mudarmos de esquema duplo com ciclosporina e corticóide para esquema tríplice, em pacientes que, por outras razōes, estavam indo bem, e eu acredito que teremos, na imensa maioria dos doentes, que mudar para um sistema tríplice e baixar a dose de ciclosporina. Em relação à observação do Dr. Danton, as alteraçōes, realmente são as que ocorrem em outras circunstâncias, alteraçōes de hipertensão pulmonar. Nós temos o equipamento no Instituto; acho que, para seguimento seqüencial, é uma importante contribuição; para um dado científico isolado absoluto, ainda está em fase de comparação de dados. Acho que a impedância é mais sujeita à crítica; os métodos não invasivos, todos eles têm um papel significativo; o ecocardiograma, a bioimpedância, como seguimento e assistência aos doentes. Muito obrigado. 